\title{
Research Article \\ Optimal Acquisition and Inventory Control for a Remanufacturing System
}

\author{
Zhigang Jiang, ${ }^{1}$ Shuo Zhu, ${ }^{1}$ Hua Zhang, ${ }^{1}$ and Yanhong Wang ${ }^{2}$ \\ ${ }^{1}$ College of Machinery and Automation, Wuhan University of Science \& Technology, Wuhan 430081, China \\ ${ }^{2}$ College of Management, Wuhan University of Science \& Technology, Wuhan 430081, China \\ Correspondence should be addressed to Zhigang Jiang; jzg100@163.com
}

Received 2 July 2013; Revised 1 September 2013; Accepted 5 September 2013

Academic Editor: Tinggui Chen

Copyright (c) 2013 Zhigang Jiang et al. This is an open access article distributed under the Creative Commons Attribution License, which permits unrestricted use, distribution, and reproduction in any medium, provided the original work is properly cited.

\begin{abstract}
Optimal acquisition and inventory control can often make the difference between successful and unsuccessful remanufacturing. However, there is a greater degree of uncertainty and complexity in a remanufacturing system, which leads to a critical need for planning and control models designed to deal with this added uncertainty and complexity. In this paper, a method for optimal acquisition and inventory control of a remanufacturing system is presented. The method considers three inventories, one for returned item and the other for serviceable and recoverable items. Taking the holding cost for returns, recoverable and remanufactured products, remanufacturing cost, disposal cost, and the loss caused by backlog into account, the optimal inventory control model is established to minimize the total costs. Finally, a numerical example is provided to illustrate the proposed methods.
\end{abstract}

\section{Introduction}

With the increasing awareness of environmental protection worldwide, the green trend of conserving the Earth's resources and protecting the environment is overwhelming. The conversation of resources is being considered from many aspects of product development and use, such as redesign, reuse, recycle, and remanufacture of products and components. Remanufacturing is a powerful product recovery option which generates products as good as new ones from old discarded ones [1]. This technique can also help to reduce the environmental impact of the product in its final disposal [2]. Growing concern for resource conservation and waste reduction led to the augmentation of remanufacturing.

Various strategic and operational aspects of used products remanufacturing have been investigated in the last decades. However, for remanufacturing, the main problem is the collection of used products with good quality at the right time and at the right inventory level [3]. One of the concerns for collection, therefore, is the design of acquisition quantity based on the remanufacturing cost and capability. Dowlatshahi [4] elaborated on how to overcome obstacles within the reverse logistics network in order to ensure a steady supply of cores and presented a framework for effective design and implementation of recycling operations. Ostlin et al. [5] identified different sources of cores and explored how to take back used products for remanufacturing from a customer-supplier relationship perspective. Korchi and Millet [6] presented a detailed practical framework for designing the reverse logistics channel for supplying reusable used modules to the production chain.

With the used product collection available, another important decision in remanufacturing is how many quantities of the available cores should be determined. Jayaraman [7] proposed an analytical approach to capture the variability of the returning condition of used products through a discrete distribution of nominal quality. Kim et al. [8] proposed a mixed integer programming model to maximize the total cost savings of a group of remanufacturing facilities by optimally deciding on the quantity of worn parts to be processed at each facility and the number of parts to purchase from a subcontractor. Li et al. [9] presented a stochastic dynamic programming based model for uncertain production planning of a remanufacturing system. Shah et al. [10] presented an optimal strategy of switching between the "cores" and virgin components with a reinforcement learning algorithm. 


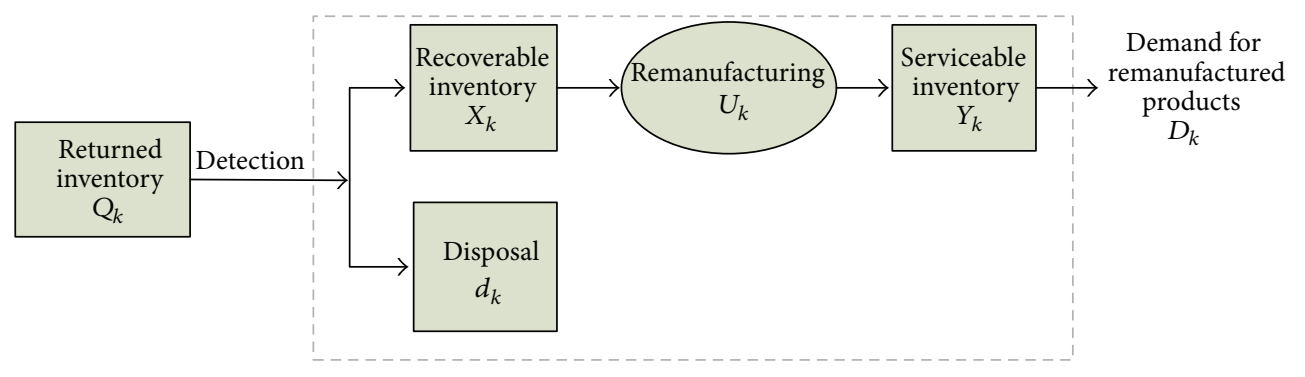

FIGURE 1: Inventory control framework of a remanufacturing system.

Denizel et al. [11] formulated a stochastic programming model for a multiperiod remanufacturing planning to determine the quantity of returned products at each quality level to be remanufactured. Karamouzian et al. [12] provided an analytical model using queuing network theory to obtain the best policy for accepting returned products. Of course, there have been many other excellent contributions in terms of the used product acquisition and quantity planning.

Used product acquisition and quantity planning have been widely recognized as an efficient tool of remanufacturing [13]. However, the uncertainty and complexity of return and demand make the production planning more complicated. Mukhopadhyay and Ma [14] studied the impact of stochastic quality of returns on remanufacturing. Tang and $\mathrm{Li}$ [15] presented a synopsis of ongoing research in uncertainty management of remanufacturing and pointed out that integrated methodologies and their evaluations in real industry practices deserve future research efforts. By matching the demand for used products with potential supply in a systematic way, an effective model is needed and crucial for maximizing the profitability of a remanufacturing system [16].

Motivated by the foregoing discussion, this paper presents an optimal method for used product acquisition and inventory control. The state variable is defined by the recoverable inventory and the serviceable inventory of remanufactured products, the decision variable is defined by the number of returned products per stage, and the Bellman equation is constructed by minimizing the expected cost during the finite stages. And the optimal acquisition and inventory control levels of the remanufacturing system can be obtained with the policy iteration method. Following the presentation of the proposed method, the method is demonstrated via a numerical example.

\section{Development of Model}

In this section, the framework, assumptions, and the proposed model for used products acquisition and inventory management are presented.

2.1. Modeling Framework. A remanufacturing system begins with the collection of the used product or parts, also named as core, followed by its remanufacturing and delivery of the remanufactured product to the client [17]. All returned used products $\left(Q_{k}\right)$ need to be detected. If the used products cannot be recoverable, then they would be disposed of by material recycling $\left(d_{k}\right)$. Of course, the used products that successfully complete the inspection phase may be placed into a recoverable inventory, and then the best quality returns $\left(U_{k}\right)$ need to be determined and remanufactured as good as new products. Meanwhile, the rest of recoverable products $\left(X_{k}\right)$ need to be stored for the next period. The remanufactured products $\left(Y_{k}\right)$ are stored as serviceable inventory, which in turn is used to feed into sales. Therefore, there are three inventories in a remanufacturing system: the returned inventory, recoverable inventory, and the serviceable inventory of remanufactured products, as depicted in Figure 1.

There are several unique characteristics which predominantly and naturally occur in the remanufacturing environment that further complicate the remanufacturing management [18], for instance, uncertainties in supply sources, uncertainties in the timing and the quantity of returns, uncertainty in quality of used products, and uncertainty in varieties of recycled used products. Due to the uncertainties in arriving timing, quality, and quantity of reverse logistics, the returned and recoverable inventory must be large so as to ensure the smoothness and continuity of remanufacturing production, and then the cost of recovery inventory will increase. For the sake of maximization of profits, the quantity of returned products and the demands of remanufactured products must be balanced in remanufacturing system [19]. In addition, the remanufacturing cores are the used parts and components, which are different in types and specifications or are variable in size changes and material performance changes, so the remanufacturing process and the process parameters are uncertain, and the lead time varies greatly. The uncertainties of remanufacturing process result in the uncertainties of the total remanufacturing cost, including purchase cost, testing cost, disassembly cost, and recovery cost.

Mindful that these problems add complexity to this field of research, the objective of this paper is to determine the optimal acquisition and inventory control to guarantee a required service level and to minimize the total costs.

2.2. Model Assumptions. Several operations, such as collection and inspection of used products, remanufacturing of as-good-as-new products, and disposal of used products unsuitable for the remanufacturing process, are considered within the system. However, a number of assumptions are made throughout this analysis in order to simplify the system 
and facilitate the modeling process by helping to focus on the most important factors. The assumptions are summarized as follows:

(1) Market demands of remanufactured products are stochastic variables.

(2) Taking into account that used products should be tested after collection and then be remanufactured, capacity of collection and inspection activities is considered to be infinite.

(3) Remanufacturing cost is a linear function of the state of returned products, and remanufacturing quantity is a linear function of batch quantity of return.

(4) The proportion of returned products which are disposed is stochastic, and the impact of used products disposal on remanufacturing production planning is not considered.

(5) Remanufacturing activity starts and ends in the same stage and ignores the uncertainties of production lead time.

2.3. Model Formulation. As described above, the $N$ stages production planning is formulated in a single used product remanufacturing system. Once a demand of the remanufacturing market is analyzed, the optimal acquisition and inventory control to minimize the total costs of a whole remanufacturing cycle need to be determined. Total costs include return cost, remanufacturing cost, disposal cost, and costs of returned, recoverable, and serviceable inventory. Due to the market demand uncertainty, there may be a backlog cost. Notations used in this paper are as follows:

$N$ : the total stages of the production plan,

$Q_{k}$ : the return of used products of stage $k$ (the decision variable),

$d_{k}$ : the disposal quantities of used products of stage $k$, $X_{k}$ : the recoverable inventory of stage $k$,

$Y_{k}$ : the serviceable inventory of remanufactured products of stage $k$,

$X_{1}$ : the initial recoverable inventory,

$Y_{1}$ : the initial serviceable inventory of remanufactured products,

$M_{x}$ : the maximum recoverable inventory,

$M_{y}$ : the maximum serviceable inventory of remanufactured products,

$U_{k}$ : the quantity of remanufacturing processing of stage $k$,

$D_{k}$ : the demand of remanufactured products of stage $k$,

$m_{k}$ : the state variable of returned products,

$a_{k}$ : the fixed cost of returned products of stage $k$,

$u$ : the return cost of used products per unit,

$s$ : the disposal cost of used products per unit,
$C_{h}$ : the holding cost of recoverable inventory per unit,

$C_{H}$ : the holding cost of serviceable inventory per unit,

$C_{p}$ : the fixed cost of remanufacturing processing,

$V_{k}$ : the variable cost of remanufacturing processing,

$C_{b}$ : the backlog cost per unit,

$W_{k}$ : the output ratio of returned products of stage $k$.

The state variable is defined by the recoverable inventory and the serviceable inventory of remanufactured products

$$
S_{k}=\left(X_{k}, Y_{k}\right) \text {. }
$$

The state transition equation is

$$
\begin{gathered}
X_{k+1}=X_{k}+Q_{k}-d_{k}-U_{k}, \\
Y_{k+1}=Y_{k}+U_{k}-D_{k} .
\end{gathered}
$$

As the remanufacturing processing quantity is a linear function of batch quantity of retur, $W_{k}$ is the yield of returned products of stage $k$, and then $U_{k}$ can be calculated by $U_{k}=$ $W_{k} Q_{k}$, where $\max \left(0, X_{k}+Q_{k}-d_{k}-M_{x}\right) \leq U_{k} \leq \min \left(\left(M_{y}-\right.\right.$ $\left.\left.Y_{k}\right),\left(X_{k}+Q_{k}-d_{k}\right)\right), Q_{k} \geq D_{k}, 0<W_{k}<1$. The action space of $Q_{k}$ is

$$
\begin{aligned}
R_{k\left(S_{k}\right)}=\left\{Q_{k} \mid \max \left(D_{k}, \frac{d_{k}-X_{k}}{1-W_{k}}\right) \leq Q_{k}\right. \\
\left.\quad \leq \min \left(\frac{M_{x}+d_{k}-X_{k}}{1-W_{k}}, \frac{M_{y}-Y_{k}}{W_{k}}\right)\right\} .
\end{aligned}
$$

The total cost of stage $k$ includes the return cost of used products (i.e., the fixed cost of transportation and the total purchase cost), inventory cost (i.e., the holding cost of recoverable and serviceable inventory), remanufacturing cost (i.e., the fixed cost of disassembly, cleaning, the variable cost of recovery, and purchase of new parts), backlog cost (i.e., cost allowance for unsatisfying the demand), and disposal cost. So, the total cost of stage $k$ can be defined as

$$
\begin{aligned}
C_{k}\left(S_{k}, Q_{k}\right)= & a_{k}+u Q_{k}+C_{h}\left[X_{k}+Q_{k}-d_{k}-U_{k}\right]^{+} \\
& +C_{H}\left[Y_{k}+U_{k}-D_{k}\right]^{+}+\left(C_{p}+V_{k} m_{k}\right) U_{k} \\
& +C_{b}\left[D_{k}-Y_{k}-U_{k}\right]^{+}+s d_{k}
\end{aligned}
$$

subject to

$$
\begin{gathered}
(X)^{+}=\max \{0, x\}, \\
0 \leq X_{k} \leq M_{x}, \\
0 \leq Y_{k} \leq M_{y} .
\end{gathered}
$$

In this model, the state variable $m_{k}$ of returned products is subject to uniform distribution $\left(0, D_{k} /\left(2 Q_{k}-D_{k}\right)\right)$ according to the statistical analysis of returned products where $m_{k}=0$ represents that the best state of the returned products, and $m_{k}=1$ indicates the worst state of the returned products. 
With the $m_{k}$ available, the expectation $E\left(m_{k}\right)$ can be calculated by $E\left(m_{k}\right)=D_{k} / 2\left(2 Q_{k}-D_{k}\right)$, and then (4) can be written as

$$
\begin{aligned}
E\left[C_{k}\left(S_{k}, Q_{k}\right)\right]= & a_{k}+u Q_{k}+C_{h}\left(X_{k}+Q_{k}-d_{k}-W_{k} Q_{k}\right) \\
& +C_{H}\left(Y_{k}+W_{k} Q_{k}-D_{k}\right) \\
& +\left(C_{p}+V_{k} \frac{D_{k}}{2\left(2 Q_{k}-D_{k}\right)}\right) W_{k} Q_{k} \\
& +C_{b}\left(D_{k}-Y_{k}-W_{k} Q_{k}\right)+s d_{k}, \\
\frac{d E\left[C_{k}\left(S_{k}, Q_{k}\right)\right]}{d Q_{k}}= & u+C_{h}-W_{k} C_{h}+W_{k} C_{H}+W_{k} C_{p} \\
& -W_{k} C_{b}-\frac{W_{k} V_{k} D_{k}^{2}}{2\left(2 Q_{k}-D_{k}\right)^{2}} .
\end{aligned}
$$

For $d E\left[C_{k}\left(S_{k}, Q_{k}\right)\right] / d Q_{k}=0$,

$Q_{k}=\frac{1}{2} D_{k}\left(1+\sqrt{\frac{V_{k}}{2\left(\left(u+C_{h}\right) / W_{k}-C_{h}+C_{H}+C_{p}-C_{b}\right)}}\right)$.

Therefore, the optimal acquisition quantity

$$
\begin{aligned}
& Q_{k}=\max \left(D_{k},\right. \\
& \frac{1}{2} D_{k}\left(1+\left(V_{k} \times\left(2 \left(\frac{u+C_{h}}{W_{k}}-C_{h}+C_{H}\right.\right.\right.\right. \\
&\left.\left.\left.\left.\left.\quad+C_{p}-C_{b}\right)\right)^{-1}\right)^{1 / 2}\right)\right) .
\end{aligned}
$$

The objective is to determine the optimal inventory control $S_{k}(k=1,2, \ldots, N)$ while minimizing the total expected cost during $N$ stages, and the objective function is defined as

$$
f_{k}\left(S_{k}\right)=\min _{\mathrm{Q}_{k} \in R_{k}\left(S_{k}\right)} \sum_{i=1}^{N} E\left\{C_{i}\left(S_{i}, Q_{i}\right)\right\}
$$

where $E()$ represents the expected cost.
According to the theory of dynamic programming, the Bellman equation of the objective function, which can represent the recursive relation, is shown as follows:

$$
\begin{aligned}
f_{k}\left(S_{k}\right)=\min _{Q_{k} \in R_{k}\left(S_{k}\right)} E\left\{C_{k}\left(S_{k}, Q_{k}\right)+f_{k+1}\left(S_{k+1}\right)\right\} \\
=\min _{Q_{k} \in R_{k}\left(S_{k}\right)} E\left\{C_{k}\left(X_{k}, Y_{k}, Q_{k}\right)+f_{k+1}\left(X_{k+1}, Y_{k+1}\right)\right\} \\
=\min _{Q_{k} \in R_{k}\left(S_{k}\right)} E\left\{C_{k}\left(X_{k}, Y_{k}, Q_{k}\right)\right. \\
+f_{k+1}\left(\left[X_{k}+Q_{k}-d_{k}-U_{k}\right]^{+},\right. \\
{\left.\left.\left[Y_{k}+U_{k}-D_{k}\right]^{+}\right)\right\}, }
\end{aligned}
$$

where

$$
\begin{gathered}
k=1, \ldots, N, \\
f_{N+1}(N+1)=0 .
\end{gathered}
$$

So, the above discussed model can be formulated as follows:

$$
\begin{aligned}
& \min _{\mathrm{Q}_{k} \in R_{k}\left(S_{k}\right)} E\left\{C_{k}\left(X_{k}, Y_{k}, Q_{k}\right)\right. \\
& +f_{k+1}\left(\left[X_{k}+Q_{k}-d_{k}-U_{k}\right]^{+},\right. \\
& \left.\left.\left[Y_{k}+U_{k}-D_{k}\right]^{+}\right)\right\}, \\
& \text {subject to } X_{k+1}=X_{k}+Q_{k}-d_{k}-U_{k} \text {, } \\
& Y_{k+1}=Y_{k}+U_{k}-D_{k} \text {, } \\
& (X)^{+}=\max \{0, x\}, \\
& R_{k\left(S_{k}\right)} \\
& =\left\{Q_{k} \mid \max \left(D_{k}, \frac{d_{k}-X_{k}}{1-W_{k}}\right) \leq Q_{k}\right. \\
& \left.\leq \min \left(\frac{M_{x}+d_{k}-X_{k}}{1-W_{k}}, \frac{M_{y}-Y_{k}}{W_{k}}\right)\right\} \\
& 0 \leq X_{k} \leq M_{x}, \quad 0 \leq Y_{k} \leq M_{y}, \\
& k=1, \ldots, N \text {, } \\
& U_{k}=W_{k} Q_{k}, \quad 0<W_{k}<1, \\
& d_{k}=Q_{k}-U_{k}-X_{k} \text {. }
\end{aligned}
$$

This model formulation can be divided into two phases for production planning. Firstly, the optimal acquisition quantity may be determined, and then the optimal inventory control model needs to be established to minimize the total costs.

2.4. Solution Algorithm. The proposed model is a dynamic programming model, which is difficult to solve, especially 
that the state at next period is not completely determined by the state and policy decision at current period (i.e., need to obtain the optimal decisions per period). We present a policy iteration approach to obtain near optimal solution for the problem. The approach starts with an arbitrary policy (an approximation to the optimal policy works best) and carries out the following steps: firstly, $S_{k}$ need to be determined. The definition of $S_{k}$ is a set of inventories, and there are equations for each state. These equations which have been presented in the model formulation can be solved iteratively, so that we can obtain the expected cost of every state; secondly, when the algorithm has converged, the solution procedure starts at the end and moves backward stage by stage each time to find the optimal policy for that stage, and it should only change the policy if the new action for some state improves the expected value; in the end, stop if it finds the optimal policy at the initial stage. We will use a numerical example to illustrate the iteration processing in the numerical study.

\section{Numerical Study}

It is assumed that the total stages number $N$ is 2 . The maximum number of inventory $M_{x}$ is 2 and $M_{y}$ is 2 ; the initial number of inventory $X_{1}$ and $Y_{1}$ is 0 , respectively. Parameter settings for the model are shown in Tables 1 and 2.

From the history data, the probability distribution of demands can be forecast for each stage. So, we can obtain the expectation of demand $E\left(D_{k}\right)$ and then replace actual products demand with the expectation demand. The distributions of the demands of remanufactured products are given in Tables 3 and 4.

According to Tables 3 and 4, the expectation of demand $E\left(D_{1}\right)$ is 1.8 and $E\left(D_{2}\right)$ is 2.2. In fact, we consider them as actual products demand. Associated with (8), the optimal acquisition quantity can be calculated: $Q_{1}$ is 2.5 and $Q_{2}$ is 3.3. According to $U_{k}=W_{k} Q_{k}$, the quantity of remanufacturing processing $U_{1}$ and $U_{2}$ is 1.25 and 1.65 , respectively. Then, through statistical analysis of large state data of return products, we can obtain the probability distribution of $m_{k}$, owing to $E\left(m_{k}\right)=D_{k} / 2\left(2 Q_{k}-D_{k}\right)$, so $E\left(m_{1}\right)$ is 0.28 , and $E\left(m_{2}\right)$ is 0.25 .

In the second stage, we can list all the probable inventory states, and according to the optimal inventory control model established in Section 2.3, using (12), the minimum expected cost of this remanufacturing system is shown in Tables 5 and 6 . The solution procedure starts at the end and moves backward stage by stage each time to find the optimal policy for that stage, and the optimal inventory arrangement can be obtained along with the minimum expected cost that comes up.

In the above analysis, the parameters are modified by the data from real remanufacturing works of used machine tools. The uniform distribution of the state variable $m_{k}$ of returned products is very important to determine the optimal acquisition quantity. To ensure the effectiveness of the model, the uniform distribution must be studied before the production preparation. When the costs and the distribution of demands
TABLE 1: Parameter settings of constants for the model.

\begin{tabular}{cccccc}
\hline$u$ & $C_{h}$ & $C_{H}$ & $C_{b}$ & $s$ & $C_{p}$ \\
\hline 3 & 1.5 & 1.5 & 11 & 0.5 & 3 \\
\hline
\end{tabular}

TABLE 2: Parameter settings of variables for the model.

\begin{tabular}{lccc}
\hline & $a_{k}$ & $V_{k}$ & $W_{k}$ \\
\hline$k=1$ & 8 & 6 & 0.5 \\
$k=2$ & 10 & 8 & 0.5 \\
\hline
\end{tabular}

TABLE 3: The distribution of the demands of remanufactured products in stage 1 .

\begin{tabular}{lccc}
\hline $\begin{array}{l}\text { Demands of remanufactured } \\
\text { products } D_{1}\end{array}$ & 1 & 2 & 3 \\
\hline Distribution $P\left(D_{1}\right)$ & 0.4 & 0.4 & 0.2 \\
\hline
\end{tabular}

TABle 4: The distribution of the demands of remanufactured products in stage 2 .

\begin{tabular}{lccc}
\hline $\begin{array}{l}\text { Demands of remanufactured } \\
\text { products } \mathrm{D}_{2}\end{array}$ & 1 & 2 & 3 \\
\hline Distribution $P\left(D_{2}\right)$ & 0.1 & 0.6 & 0.3 \\
\hline
\end{tabular}

are deterministic, the optimal production plan of period $k$ is completely determined by its state, which is defined by the recovery inventory and the serviceable inventory in this model. From (8), the probable optimal quantity of returned products is 2.5 in stage 1 and 3.3 in stage 2, respectively. From Tables 5 and 6 , when $(0,0)$ is the inventory state of stage 1 and $(0,1)$ is the inventory state of stage 2 , the minimum expected cost during the two periods is 55.055 .

\section{Summary and Conclusions}

The success of a remanufacturing business is very dependent on the acquisition and inventory management in order to satisfy the demand for remanufactured products. In this paper, optimal acquisition and inventory control method is proposed for a remanufacturing system with uncertain demand. The state variable is defined by the recoverable inventory and the serviceable inventory of remanufactured products, and the objective is to determine the quantities that have to be remanufactured in these periods in order to minimize the total cost. This method can be used for remanufacturing enterprise to make the production plan in the uncertain environment.

With the development of remanufacturing, the returns amount will be large and the state of returned products will be more and more unpredictable. Thus, this model has much to be desired; in a further research, the sensibility of the optimal production-inventory policy on changes of quantity of return products should be examined. The interaction between the state of recycling products and the cost of remanufacturing processing should also be given deeper consideration. 
TABle 5: The probable state and its expected cost of stage 2.

\begin{tabular}{lcc}
\hline State $(k=2)$ & Disposal quantity & Expected cost of stage 2 \\
$S_{2}=\left(X_{2}, Y_{2}\right)$ & $d_{2}=Q_{2}-U_{2}-X_{2}$ & 32.406 \\
\hline$(0,0)$ & 1.65 & 27.030 \\
$(0,1)$ & 1.65 & 28.531 \\
$(0,2)$ & 1.65 & 35.406 \\
$(1,0)$ & 0.65 & 29.531 \\
$(1,1)$ & 0.65 & 31.031 \\
$(1,2)$ & 0.65 & $f_{2}$ \\
\hline
\end{tabular}

TABLE 6: The probable state and its expected cost of stage 1.

\begin{tabular}{|c|c|c|c|}
\hline $\begin{array}{l}\text { State }(k=1) \\
S_{1}=\left(X_{1}, Y_{1}\right)\end{array}$ & $\begin{array}{l}\text { Disposal quantity } \\
d_{1}=Q_{1}-U_{1}-X_{1}\end{array}$ & $\begin{array}{l}\text { Expected cost of stage } 1 \\
f_{1}\end{array}$ & $\begin{array}{c}\text { Accumulative total } \\
\text { expected cost } \\
f_{1}+f_{2}\end{array}$ \\
\hline$(0,0)$ & 1.65 & 28.025 & 55.055 \\
\hline
\end{tabular}

\section{Acknowledgments}

The work described in this paper was supported by the National Natural Science Foundation of China (51205295) and the National Science and Technology Supporting Program (no. 2012BAF02B01). These financial contributions are gratefully acknowledged. The authors also thank the anonymous reviewers whose reviews helped in improving the paper.

\section{References}

[1] A. Rashid, F. M. A. Asif, P. Krajnik, and C. M. Nicolescu, "Resource conservative manufacturing: an essential change in business and technology paradigm for sustainable manufacturing," Journal of Cleaner Production, vol. 57, no. 15, pp. 166-177, 2013.

[2] D. C. A. Pigosso, E. T. Zanette, A. G. Filho, A. R. Ometto, and H. Rozenfeld, "Ecodesign methods focused on remanufacturing," Journal of Cleaner Production, vol. 18, no. 1, pp. 21-31, 2010.

[3] S. Pokharel and Y. Liang, "A model to evaluate acquisition price and quantity of used products for remanufacturing," International Journal of Production Economics, vol. 138, no. 1, pp. 170-176, 2012.

[4] S. Dowlatshahi, "A strategic framework for the design and implementation of remanufacturing operations in reverse logistics," International Journal of Production Research, vol. 43, no. 16, pp. 3455-3480, 2005.

[5] J. Ostlin, E. Sundin, and M. Bjorkman, "Importance of closedloop supply chain relationships for product remanufacturing," International Journal of Production Economics, vol. 115, no. 2, pp. 336-348, 2008.

[6] A. E. Korchi and D. Millet, "Designing a sustainable reverse logistics channel: the 18 generic structures framework," Journal of Cleaner Production, vol. 19, no. 6-7, pp. 588-597, 2011.

[7] V. Jayaraman, "Production planning for closed-loop supply chains with product recovery and reuse: an analytical approach," International Journal of Production Research, vol. 44, no. 5, pp. 981-998, 2006.

[8] K. Kim, I. Song, J. Kim, and B. Jeong, "Supply planning model for remanufacturing system in reverse logistics environment,"
Computers and Industrial Engineering, vol. 51, no. 2, pp. 279287, 2006.

[9] C. Li, F. Liu, H. Cao, and Q. Wang, "A stochastic dynamic programming based model for uncertain production planning of re-manufacturing system," International Journal of Production Research, vol. 47, no. 13, pp. 3657-3668, 2009.

[10] P. Shah, A. Gosavi, and R. Nagi, "A machine learning approach to optimise the usage of recycled material in a remanufacturing environment," International Journal of Production Research, vol. 48, no. 4, pp. 933-955, 2010.

[11] M. Denizel, M. Ferguson, and G. G. C. Souza, "Multiperiod remanufacturing planning with uncertain quality of inputs," IEEE Transactions on Engineering Management, vol. 57, no. 3, pp. 394-404, 2010.

[12] A. Karamouzian, E. Teimoury, and M. Modarres, "A model for admission control of returned products in a remanufacturing facility using queuing theory," The International Journal of Advanced Manufacturing Technology, vol. 54, no. 1-4, pp. 403412, 2011.

[13] O. Kaya, "Incentive and production decisions for remanufacturing operations," European Journal of Operational Research, vol. 201, no. 2, pp. 442-453, 2010.

[14] S. K. Mukhopadhyay and H. Ma, "Joint procurement and production decisions in remanufacturing under quality and demand uncertainty," International Journal of Production Economics, vol. 120, no. 1, pp. 5-17, 2009.

[15] Y. Tang and C. B. Li, "Uncertainty management in remanufacturing: a review," in Proceedings of IEEE International Conference on Automation Science and Engineering, pp. 52-57, Seoul, Republic of Korea, August 2012.

[16] H. K. Aksoy and S. M. Gupta, "Optimal management of remanufacturing systems with server vacations," The International Journal of Advanced Manufacturing Technology, vol. 54, no. 912, pp. 1199-1218, 2011.

[17] V. D. R. Guide and V. Jayaraman, "Product acquisition management: current industry practice and a proposed framework," International Journal of Production Research, vol. 38, no. 16, pp. 3779-3800, 2000.

[18] G. Ferrer and J. M. Swaminathan, "Managing new and differentiated remanufactured products," European Journal of Operational Research, vol. 203, no. 2, pp. 370-379, 2010. 
[19] A. M. A. El Saadany and M. Y. Jaber, "A production/remanufacturing inventory model with price and quality dependant return rate," Computers and Industrial Engineering, vol. 58, no. 3, pp. 352-362, 2010. 


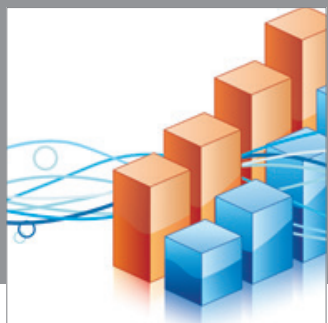

Advances in

Operations Research

mansans

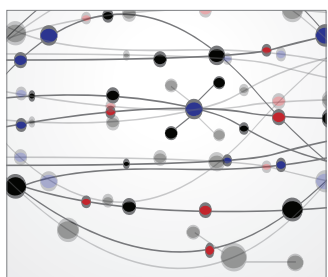

The Scientific World Journal
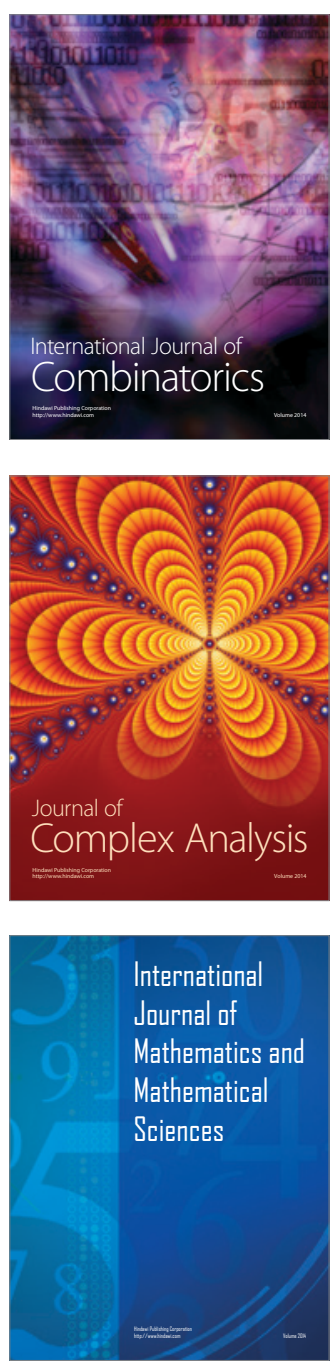
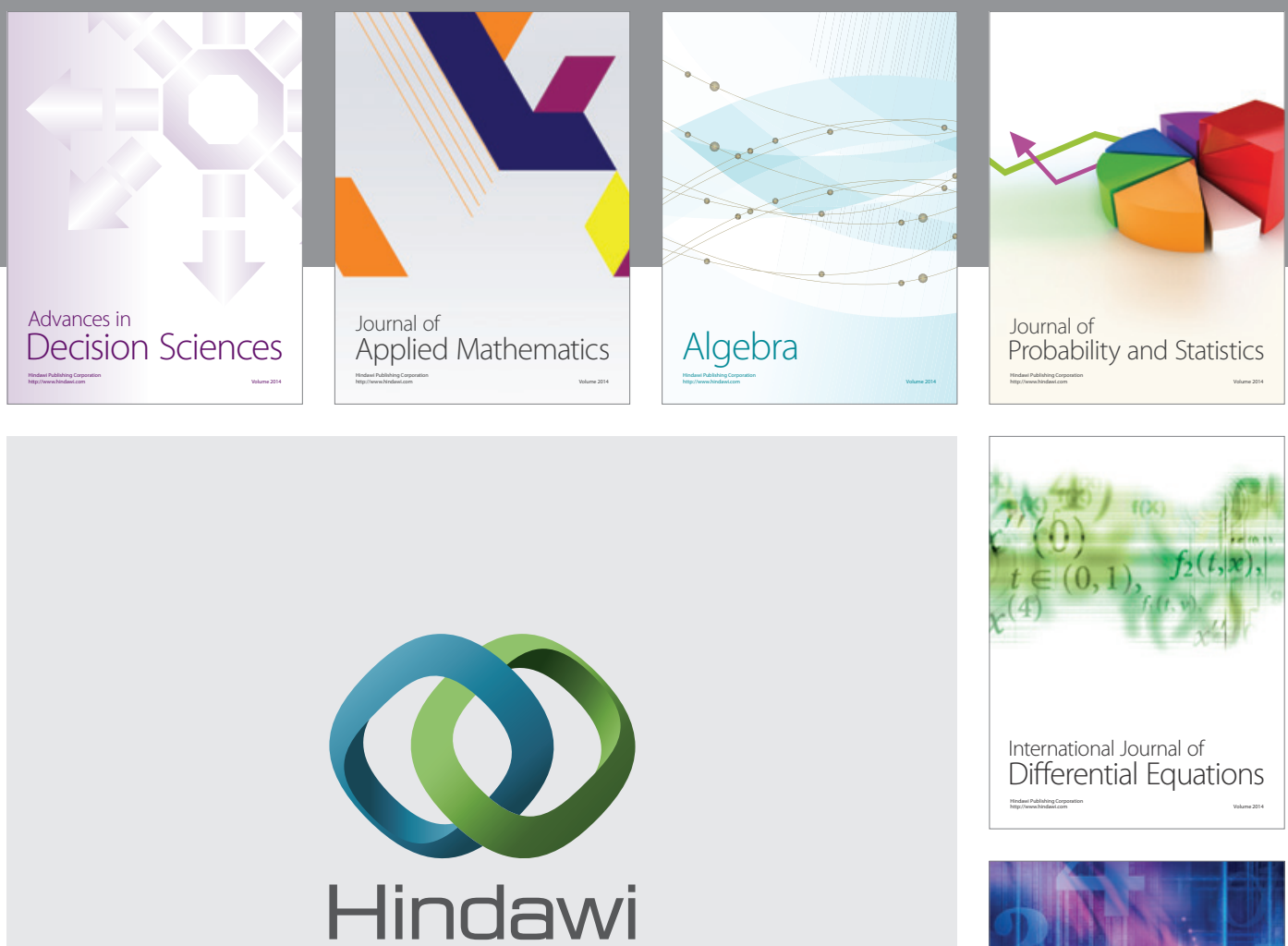

Submit your manuscripts at http://www.hindawi.com
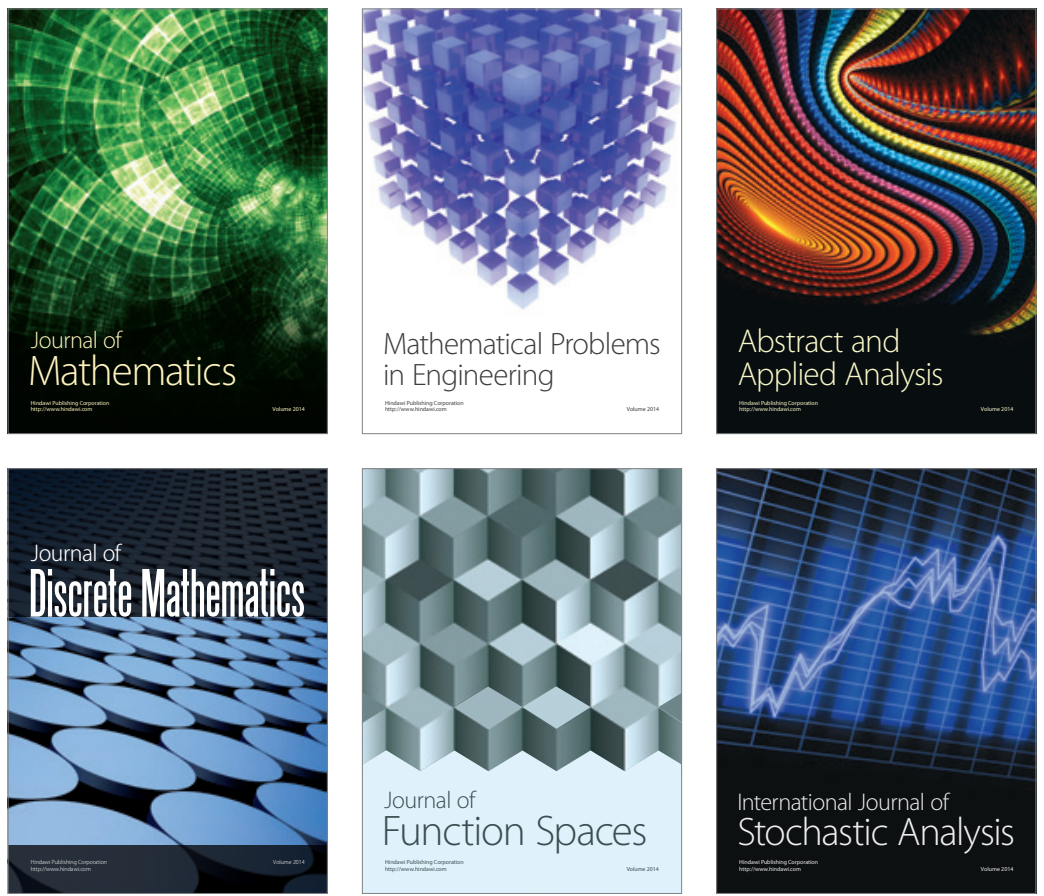

Journal of

Function Spaces

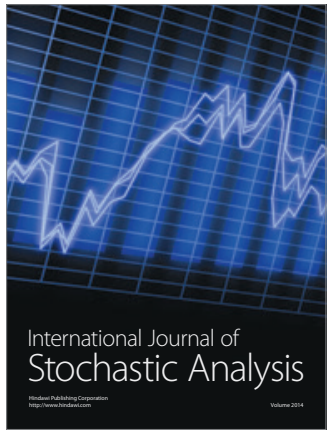

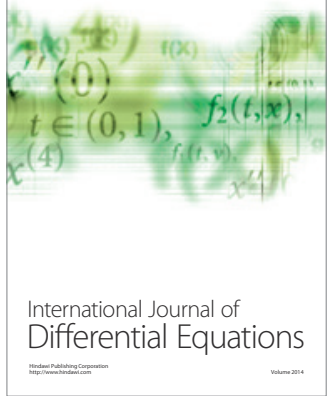
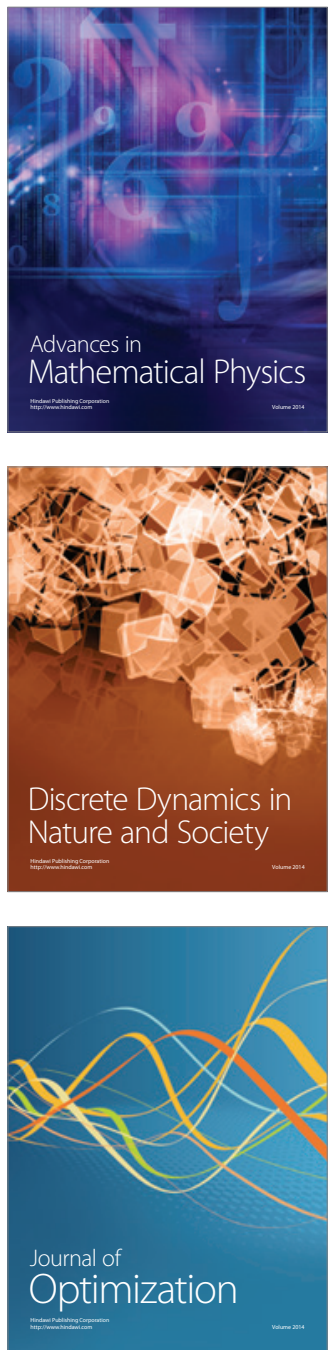